\title{
The Drosophila cellularization gene nullo produces a blastoderm-specific transcript whose levels respond to the nucleocytoplasmic ratio
}

\author{
Lesilee Simpson Rose ${ }^{1}$ and Eric Wieschaus \\ Department of Molecular Biology, Princeton University, Princeton, New Jersey 08544 USA
}

\begin{abstract}
The initial development of the Drosophila embryo is characterized by rapid nuclear mitosis without cytokinesis. After 13 such mitoses, a coordinated cell division process called cellularization occurs, during which membranes simultaneously enclose each nucleus in a cell. Cellularization requires the establishment of a hexagonal network of actin and myosin filaments in the cortex of the embryo; the filaments are located on the cytoplasmic face of the invaginating membrane furrows. Zygotic expression of the nullo gene is essential for the maintenance of an intact actin-myosin network. We have cloned the nullo gene and present its sequence as well as a characterization of nullo transcript levels in wild-type and mutant embryos. The nullo gene encodes a predicted protein of 213 amino acids, a large proportion of which is basic. nullo transcripts are first detectable at nuclear cell cycle 11, peak in accumulation at the end of cycle 13, and disappear rapidly as cellularization begins. The gene does not appear to be expressed at any other time in the life of the organism. The normal accumulation of nullo transcripts does not require gene activity of other zygotic cellularization genes. The regulation of nullo RNA levels during cycle 14, however, is coupled to the nucleocytoplasmic ratio, which also controls the cessation of rapid, synchronous mitosis just before cellularization.
\end{abstract}

[Key Words: Drosophila; blastoderm; nullo; cytokinesis; nucleocytoplasmic ratio]

Received February 18, 1992; revised version accepted April 10, 1992.

Cellularization is one aspect of an important transition period for the Drosophila embryo. Before cellularization, there are 13 rapid, nearly synchronous mitoses without cytokinesis; the nuclear migration that accompanies these mitoses results in a syncytial blastoderm embryo with nuclei distributed in a peripheral monolayer. During cellularization in nuclear cycle 14, membranes invaginate and subdivide the embryo into individual cells. This process is associated with a rapid restructuring of the cytoskeleton. During the four cell cycles preceding cellularization, actin filaments and associated proteins are organized in caps underlying membrane protrusions above each nucleus. The caps undergo dynamic reorganizations that are coupled to the syncytial mitoses (Warn et al. 1984; Karr and Alberts 1986; Miller et al. 1989|. At the beginning of cycle 14, part of the actin-based cytoskeleton is organized into a new structure, the actinmyosin hexagonal network (Fig. 1A). The network provides a structural guide and possibly the contractile force for the synchronous invagination of membranes during cellularization (Warn et al. 1980; Warn and Magrath 1983; Katoh and Ishikawa 1989; Warn and Robert-

${ }^{1}$ Present address: Section of Genetics and Development, Biotechnology Building, Cornell University, Ithaca, New York 14853 USA.
Nicoud 1990; Young et al. 1991). Concomitant with the changes in the actin-based cytoskeleton, microtubules form a structure that appears to be responsible for the nuclear elongation that occurs at the beginning of cycle 14. In addition, interactions between adjacent asters are proposed to be responsible for the positioning of the membrane furrows, but it is unclear whether microtubules play any role in membrane invagination per se (Fullilove and Jacobson 1971; Zalokar and Erk 1976; Foe and Alberts 1983).

The early changes in the cytoskeleton that accompany the syncytial mitoses appear to be under the control of maternally expressed genes. Many of the major components of the hexagonal network are also undoubtedly encoded by maternally expressed genes, as there are only a small number of zygotic genes required for cellularization (Merrill et al. 1988; Wieschaus and Sweeton 1988). The phenotypes associated with the removal of these zygotically acting genes suggest that they may act on the factors already present (e.g., actin and myosin) to regulate certain aspects of the cellularization process. The study of these zygotic genes may thus provide an important entry point into understanding the control of cytoskeletal dynamics.

After cellularization, mitosis resumes, but the divi- 
Figure 1. Wild-type and nullo embryos were stained with rhodamine-phalloidin to reveal actin filaments (surface view). In wild-type embryos $(A)$ during early cycle 14 , actin filaments become organized into a hexagonal network that is present on the cytoplasmic face of the invaginating membrane furrows. In nullo mutant embryos $(B)$, a network forms but is then disrupted, yielding regions with little or no actin present; as a result, multinucleate cells form.
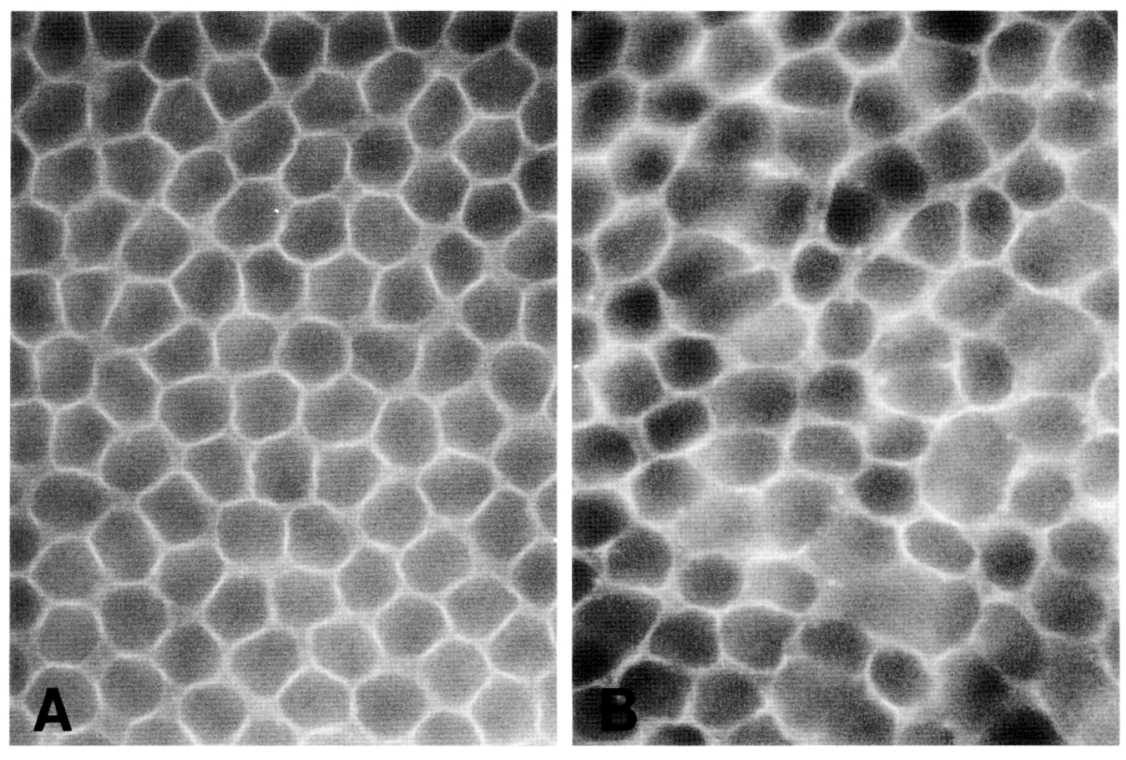

sions are accompanied by cytokinesis and are no longer synchronous (Zalokar and Erk 1976; Foe and Alberts 1983). Thus, cycle 14 marks a transition in the mode of mitosis, as well as the cellular state of the embryo. In addition, the first visible morphological requirement for the activity of zygotic genes is just prior to and during cycle 14 (Merrill et al. 1988; Wieschaus and Sweeton 1988). The coincidence of these events during the cycle 14 transition raises interesting questions about the timing of developmental events. How is the cessation of rapid mitosis linked to the initiation of cellularization? How is that timing related to the general transcriptional activation of zygotic genes during the syncytial stages preceding cycle 14? Studies by Edgar et al. (1986a) suggest that the cycle 14 transition events can be uncoupled in certain mutant backgrounds. The molecular characterization of genes required for cellularization provides specific tools for understanding the inter-relatedness of cellularization and other aspects of the cycle 14 transition.

Our previous morphological and genetic data sug. gested that one of the early-acting zygotic genes, nullo, is required for the stability of the actin-myosin network during cellularization. Embryos deleted for the nullo gene initially form a normal hexagonal network, but the network becomes disrupted early during membrane invagination (Fig. 1B). This results in the formation of multinucleate cells, and the mutant embryos die before hatching (Simpson and Wieschaus 1990). We have cloned the nullo gene and analyzed the temporal and spatial pattern of nullo transcripts as a first step toward understanding its role at the molecular level. The nullo gene encodes a novel protein with many basic amino acid residues. The pattern of nullo RNA accumulation in wildtype and mutant backgrounds suggests that the temporal control of nullo RNA levels is coupled to other cycle 14 events. In addition, we explore the relationship between the nullo gene and serendipity-alpha (sry-alpha), another cellularization gene with a very similar mutant phenotype.

\section{Results \\ Molecular isolation of the nullo gene}

Previous complementation data mapped the nullo gene to the 6F1-2 region of the X chromosome /Wieschaus and Sweeton 1988; Simpson and Wieschaus 1990). Fifty-four kilobases of a $\lambda$ phage chromosomal walk in the $6 F 1-2$ region were kindly provided to us by J. Lim (F. Sheen, J. Lim, and M.J. Simmons, in prep.). Hybridization of phage DNA to polytene chromosomes and Southern genomic blots suggested that several deficiencies that produce the nullo phenotype had breakpoints within the cloned region. The area potentially containing the nullo gene was defined more precisely by hybridization of subclones of the phage to Southern blots of genomic DNA from various nullo deficiencies and alleles. The results showed that deletions and rearrangements genetically characterized as emanating from both the proximal and distal margins of the nullo gene had breakpoints within or near the same 4.5-kb EcoRI fragment (Fig. 2).

We reasoned that nullo transcripts must be present in RNA extracted from 0 - to 4-hr embryos, because nullo is required zygotically for cellularization $(2.5-3.25 \mathrm{hr}$ postlaying). To identify regions likely to encode the nullo gene, labeled cDNA made from poly $(\mathrm{A}){ }^{+}$RNA extracted from 0- to 4-hr embryos was hybridized to Southern blots of phage and subcloned DNA. The cDNA probe hybridized to a 4.5- and a 5.6-kb EcoRI fragment; in subsequent hybridizations of Northern blots with subcloned DNA, only these two fragments hybridized to transcripts (Fig. 2). The $4.5-\mathrm{kb}$ EcoRI fragment is affected by all of the nullo mutations tested, suggesting that the nullo gene is contained within this region. The 4.5-kb EcoRI fragment hybridizes to a single transcript of $\sim 1.0 \mathrm{~kb}$ in RNA from 0- to 4-hr embryos. 


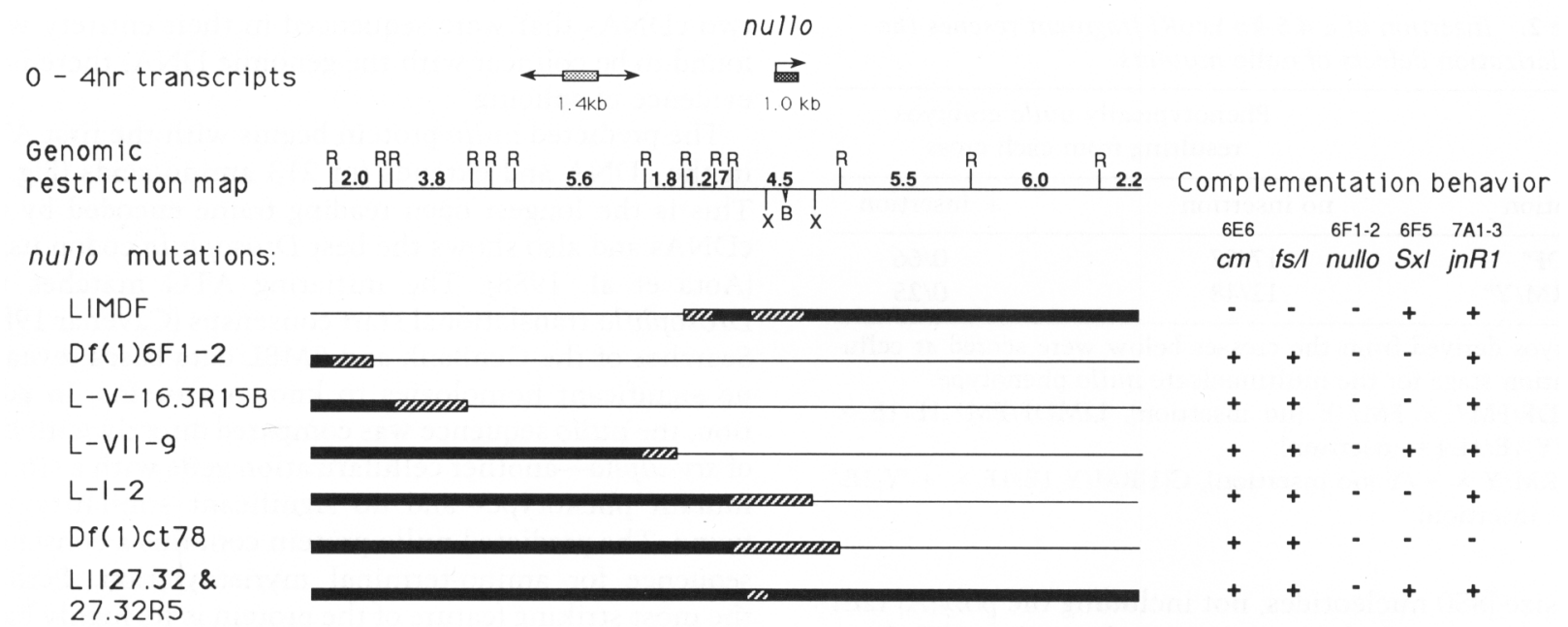

Figure 2. Molecular map of the nullo region. The EcoRI (R) restriction map of $41 \mathrm{~kb}$ of the $54 \mathrm{~kb}$ of DNA provided by J. Lim (F. Sheen, J. Lim, and M.J. Simmons, in prep.) is shown. Restriction sites for BamHI (B) and XhoI (X) near the nullo gene are also indicated. Regions for which there are corresponding transcripts in 0- to 4-hr embryos are denoted by stippled bars above the restriction map. A $1.0-\mathrm{kb}$ transcript maps to the 4.5-kb EcoRI fragment as shown; that genomic fragment contains the nullo gene, based on transformation rescue data. The only other transcript present in RNA extracted from 0- to 4-hr embryos maps within the 5.6-kb EcoRI fragment. Below the restriction map is shown the molecular characterization of various deficiencies and alleles of the nullo gene [(solid bar) DNA present; (hatched bar) uncertainty in the location of the rearrangement breakpoint; (line) DNA absent), as determined by hybridization of subcloned DNA to Southern blots of mutant DNAs (for details, see Materials and methods). The specific location of the DF(1)6F1-2 breakpoint was provided by F. Sheen [1990; referred to as Df(1)6F in that report]; our results are consistent. The Southern analysis of LIMDF suggests that this mutation consists of a deletion coupled with an inversion between the regions designated with hatched boxes |and see Materials and methods|. The rearrangement in the L-II-27.32 chromosome appears to be $5^{\prime}$ to the nullo gene. F. Sheen \{1990; L-II-27 = S3) has characterized this lesion as an insertion of a gypsy transposable element, whose direction of transcription is toward the nullo gene. Complementation data for each mutation and known genes in the region are shown at right. $(+\mid$ Complements. The cytological location is shown above each gene (for details, see Simpson and Wieschaus 1990).

Transformation rescue of nullo mutants using the 4.5-kb EcoRI fragment

To prove that the $4.5-\mathrm{kb}$ fragment encodes the nullo gene, the fragment was tested for its ability to complement nullo mutations using P element-mediated transformation (Spradling and Rubin 1982). Three independent lines containing transposons carrying the $4.5-\mathrm{kb}$ EcoRI fragment were obtained and crossed or recombined into nullo mutant backgrounds. All three insertions rescued the embryonic lethality associated with nullo mutations (Table 1). To confirm that the rescue to viability was the result of restoring normal cellularization, embryos from nullo mutant lines carrying the autosomal insertion $1 \mathrm{E}$ were examined for the multinucleate cell phenotype indicative of nullo mutants. Two copies of the insertion completely rescued the cellularization defects of the strong mutation LIMDF, as well as those of embryos deleted for the entire $\mathrm{X}$ chromosome (Table 2). A single copy was sufficient to rescue two weaker mutations (not shown).

The nullo gene encodes a novel, highly basic protein

The combination of Southern analysis and transformation rescue demonstrates that the $4.5-\mathrm{kb}$ EcoRI fragment encodes the nullo gene. The $4.5-\mathrm{kb}$ fragment was used as a probe to screen two 0- to 4-hr embryo cDNA libraries. The cDNAs obtained hybridize to the same $1.0-\mathrm{kb} 0-$ to 4-hr transcript seen with the genomic probe. The sequence of the nullo gene was determined by dideoxy sequencing of the cDNAs and the corresponding genomic DNA (for details, see Materials and methods). Three independent cDNAs from one library (Brown and Kafatos 1988) appear to be full length for the following reasons.

Table 1. Insertions of a 4.5-kb genomic EcoRI fragment rescue the embryonic lethality associated with nullo mutations

\begin{tabular}{|c|c|c|c|}
\hline \multirow[b]{2}{*}{ Mutation (m) } & \multicolumn{3}{|c|}{ Adult viability } \\
\hline & m/FM7; insertion/ + & $\mathrm{m} / \mathrm{Y}$ & $\mathrm{m} / \mathrm{Y} ;$ insertion $/+$ \\
\hline Df(1)6F1-2 & 73 & 0 & 74 \\
\hline LIMDF $^{\mathrm{b}}$ & 9 & 0 & 4 \\
\hline $\mathrm{L}-\mathrm{II}-27-32,51 \mathrm{~A}^{\mathrm{c}}$ & 26 & 0 & 10 \\
\hline L-V-16R15B, $1 \mathrm{~A}^{\mathrm{d}}$ & 49 & 0 & 21 \\
\hline
\end{tabular}

a,bFemales carrying a nullo mutation/FM7 were mated to FM7/ Y;insertion $1 \mathrm{E}[\mathrm{w}+] /+$ to produce the genotypes shown above (FM7/FM7 not included). LIMDF deletes a postembryonic lethal mutation in addition to nullo. The $44 \%$ viability reflects survival to the pharate stage.

${ }^{c, d}$ Two independent $X$-linked insertions were recombined onto the L-II-27-32 and L-V-16R15B chromosomes (see Materials and methods). Females carrying the recombinant chromosome balanced by FM7 were mated to FM $7 / Y$ males. The data for $\mathrm{m} / \mathrm{Y}$ controls for these two crosses were obtained from nonrecombinant crosses. 
Table 2. Insertion of $a 4.5-\mathrm{kb}$ EcoRI fragment rescues the cellularization defects of nullo mutants

\begin{tabular}{lcc}
\hline & \multicolumn{2}{c}{$\begin{array}{c}\text { Phenotypically nullo embryos } \\
\text { resulting from each cross }\end{array}$} \\
\cline { 2 - 3 } Mutation & no insertion & + insertion \\
\hline LIMDF $^{\mathrm{a}}$ & $17 / 57$ & $0 / 66$ \\
$\mathrm{C}(1) \mathrm{RM} / \mathrm{Y}^{\mathrm{b}}$ & $12 / 48$ & $0 / 25$ \\
\hline
\end{tabular}

Embryos derived from the crosses below were scored at cellularization stage for the multinucleate nullo phenotype.

${ }^{a} \mathrm{LIMDF} / \mathrm{FM} 7 \times \mathrm{FM} 7 / \mathrm{Y}$ (no insertion), LIMDF/FM7;1E/1E $\times$ $\mathrm{FM} 7 / \mathrm{Y} ; 1 \mathrm{E} / 1 \mathrm{E}$ (+ insertion).

${ }^{\mathrm{b}} \mathrm{C}(1) \mathrm{RM} / \mathrm{Y} \times+/ \mathrm{Y}$ (no insertion), $\mathrm{C}(1) \mathrm{RM} / \mathrm{Y} ; 1 \mathrm{E} / 1 \mathrm{E} \times+/ \mathrm{Y} ; \mathrm{lE} /$ IE $(+$ insertion).

The size [ 850 nucleotides, not including the poly(A) tail] is consistent with that seen on Northern blots. All three have an identical 5 '-terminal sequence that matches the Drosophila transcriptional start consensus (Hultmark et al. 1986) and is preceded by a noncoded G. This initial nucleotide is thought to be the result of reverse transcription of the mRNA cap during cDNA production (Brown et al. 1989; Ketchum et al. 1990; Karess et al. 1991). A fourth cDNA had an incomplete $5^{\prime}$ end. The two cDNAs that were sequenced in their entirety were found to be colinear with the genomic DNA; there is no evidence of splicing.

The predicted nullo protein begins with the first ATG in the cDNA and extends for 213 amino acids (Fig. 3). This is the longest open reading frame encoded by the cDNAs and also shows the best Drosophila codon usage (Aota et al. 1988). The initiating ATG matches the Drosophila translational start consensus (Cavenar 1987). Searches of the GenBank and EMBL data bases revealed no significant homologies to known proteins. In addition, the nullo sequence was compared directly with that of sry-alpha - another cellularization gene with a similar mutant phenotype-and no significant similarity was found. The predicted nullo protein contains a consensus sequence for amino-terminal myristoylation. Perhaps the most striking feature of the protein is its highly basic nature. The amino acid sequence includes 24 arginines and 17 lysines and has a predicted pI of 11.39 .

\section{The nullo gene is transcribed exclusively just prior} to cellularization

The nullo cDNA hybridizes to a single $1.0-\mathrm{kb}$ transcript in RNA extracted from 0 - to 4 -hr embryos. This tran-

\footnotetext{
GGTACCTGATCCTTTCAGATT TTCGGTATTTTCGGTATATATGCCCGCCGCTCGATGGCAATCAGCATCAGTTGTCCAACAACAGTTACACCGCTAACAACGTTCTCCAAAACAATATTA 1 G TATATATTAATATAT TACGAACT TGTGAC TATACCATTCTCAAGAAATCTCAAAATGGGCAGCACACATTCCGCTGAGAAGGTAAAGAGCGTCGAGGACTCGACCAGTCCTGCAAATCCT

Figure 3. The sequence of the nullo gene. The sequence of the nullo gene, as derived from genomic and cDNA sequencing, is shown. $(\nabla)$ The $5^{\prime}$ end of the three independent cDNAs that are thought to be full length $; \star$ ) two sites of polyadenylation. The putative TATA and polyadenylation signals are underlined. The predicted translation product begins with the first ATG in the cDNA. Another ATG is farther upstream in the genomic DNA, in-frame with this open reading frame; but because the cDNAs appear to be full length /see text), this ATG would not appear in the mRNA. The potential amino-terminal myristoylation site is in boldface type. Sequence analysis also identified the presence of several possible sites of phosphorylation (not shown). A fourth cDNA began at position 113 of the sequence above and was preceded by 21 nucleotides apparently derived from the $3^{\prime}$ end of the transcript. That cDNA also showed nucleotide differences at positions 139 (A), 174 (G), and 587-588 (CG); the last would produce an amino acid change from valine to alanine. These latter differences are presumably the result of polymorphisms between the two cDNA libraries used. Sequence data for the nullo gene have been submitted to the EMBL data library under accession number X65444.
} 
script is not detectable on Northern blots of RNA from other developmental stages (Fig. 4). The cDNA was also used as a probe for in situ hybridizations to whole-mount embryos, ovaries, and imaginal discs, using the digoxigenin method (Tautz and Pfeifle 1989). Consistent with the Northern blot results, only syncytial blastodermstage embryos showed significant hybridization with the nullo probe (Fig. 5; described below). A very low, variable level of apparent hybridization was present in cleavage and postcellularization-stage embryos (Fig. $5 \mathrm{~A}, \mathrm{H}$ ), and in ovaries and imaginal discs (not shown). We believe this hybridization to be nonspecific background, because similar levels were detected in embryos hemizygous for deletions of the nullo region (not shown), and Northern blot analysis revealed no transcripts at later stages or in unfertilized eggs. Thus, we conclude that the mullo gene is expressed zygotically during a narrow window of time
A

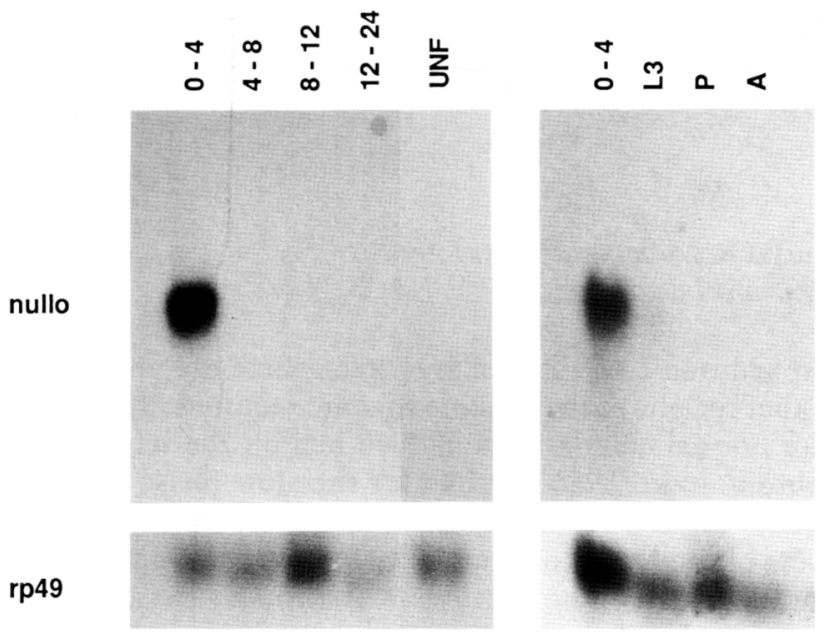

Figure 4. Temporal pattern of nullo transcripts. Hybridization of a cDNA probe to Northern blots shows that the nullo transcript $(\sim 1 \mathrm{~kb})$ is present only in 0 - to 4 -hr embryos. The blots were reprobed with DNA from the ribosomal protein 49 (rp49) gene as a control for RNA loading. $(A)$ Northern blot of poly $(\mathrm{A})^{+}$ RNA extracted from 0- to 4-, 4- to 8-, 8- to 12-, 12- to 24-hr, and unfertilized 0 - to $4-\mathrm{hr}$ (UNF) embryos; $\sim 10 \mu \mathrm{g}$ of RNA was loaded per lane. Lanes that contained no RNA were spliced out to juxtapose the 12- to 24-hr and UNF lanes. $(B)$ Northern blot of total RNA from 0 - to 4-hr embryos, third instar larvae, pupae, and adults (males). Approximately $20 \mu \mathrm{g}$ of RNA was loaded per lane. In similar experiments, no hybridization was detected in total RNA from adult females or first- and second-instar larvae. A weakly cross-hybridizing, higher-molecular-weight transcript is detected in pupae. In this experiment, a single-stranded probe complementary to the nullo transcript (but still containing 97 nucleotides of plasmid sequences) was used. Using this probe, or including nonlabeled Bluescript in the hybridization (not shown) as a nonspecific competitor, greatly reduced the intensity of cross-hybridization, as compared with other experiments in which a doubled-stranded, plasmid-based probe was used. Transcripts of this size were never detected in 0- to 4-hr embryo RNA. Thus, we believe that this transcript is not derived from the nullo gene. just before cellularization. The nullo gene does not appear to be expressed at other times in development when conventional cytokinesis events are occurring.

The spatial and temporal pattern of nullo transcripts during early embryogenesis was characterized using in situ hybridizations. In wild-type embryos, the first hybridization signal detectable above background is in cycle 11 embryos. By mitosis of cycle 12, all embryos have nullo RNA in the cortical cytoplasm (Fig. 5B). The level of nullo RNA increases as embryos progress through the thirteenth nuclear cycle, and nullo RNA accumulation peaks during the mitosis that separates cycles 13 and 14 (Fig. 5C,D). As the nuclei become hexagonally packed and begin to elongate during early cycle 14 , the levels of nullo transcript decrease rapidly (Fig. 5E,F). By the time the cellularization front (the base of the invaginating membrane furrows) is visible, the nullo RNA levels are usually lower than those detectable in cycle 11 embryos. Embryos in which the membranes have reached the bases of the nuclei never stain above background (Fig. $5 \mathrm{G})$. The time course of nullo transcript accumulation is shown schematically in Figure 6, which shows a visual tabulation of RNA levels made by scoring the darkness of the alkaline phosphatase reaction precipitate (see Materials and methods). Although the method is too subjective to assess absolute levels of RNA, it provides a good means for comparing relative peaks and declines in RNA levels, as well as summarizing data from a large number of embryos.

There is nullo RNA throughout the entire cortex of the embryo, but the distribution of RNA is not uniform. The poles of the embryo often show less RNA accumulation than the rest of the embryo. There are also broad bands of heavier RNA accumulation, which are most apparent in cycle 14 embryos when nullo RNA levels are decreasing (Fig. 5E). The banded pattern is distinguishable in some cycle 13 embryos but not at earlier stages.

sry-alpha gene activity is not required for normal nullo expression

The sry-alpha gene encodes a $58-\mathrm{kD}$ protein that appears to be associated with the actin-myosin cytoskeletal network during cellularization (Schweisguth et al. 1990). Because deletion of sry-alpha leads to a slightly weaker, but very similar, phenotype to that of nullo mutations (Wieschaus and Sweeton 1988; E. Schejter, pers. comm.), the expression pattern of the two genes was compared. The sry-alpha gene also produces a blastoderm-specific transcript (James and Vincent 1986), but the temporal pattern of accumulation is slightly different from that of the nullo gene. Using the whole-mount in situ technique, we have confirmed earlier results obtained for accumulation using tritiated probes (Fig. 7A-C; James and Vincent 1986; Schweisguth et al. 1989|. A low level of sry-alpha RNA was detected during syncytial stages. The RNA levels increase in early cycle 14 embryos, with the highest levels being reached at about the time cell membranes first appear. During cycle 14, the transcripts 
Figure 5. In situ hybridization to nullo transcripts in wild-type embryos during early embryogenesis. Anterior is to the left. (A) Cleavagestage embryo; $(B)$ cycle 12 embryo, interphase; $(C)$ cycle 13 embryo, interphase; $(D)$ cycle $13 \mathrm{em}$ bryo, mitosis; $(E)$ cycle 14 embryo, early interphase before nuclear elongation; $(F)$ cycle $14 \mathrm{em}$ bryo during nuclear elongation; $(G)$ cycle $14 \mathrm{em}$ bryo, with membranes invaginated to bases of nuclei; $(H)$ extended germ-band-stage embryo. Staging of embryos is based on morphology and density of Hoechst-stained nuclei (data not shown).

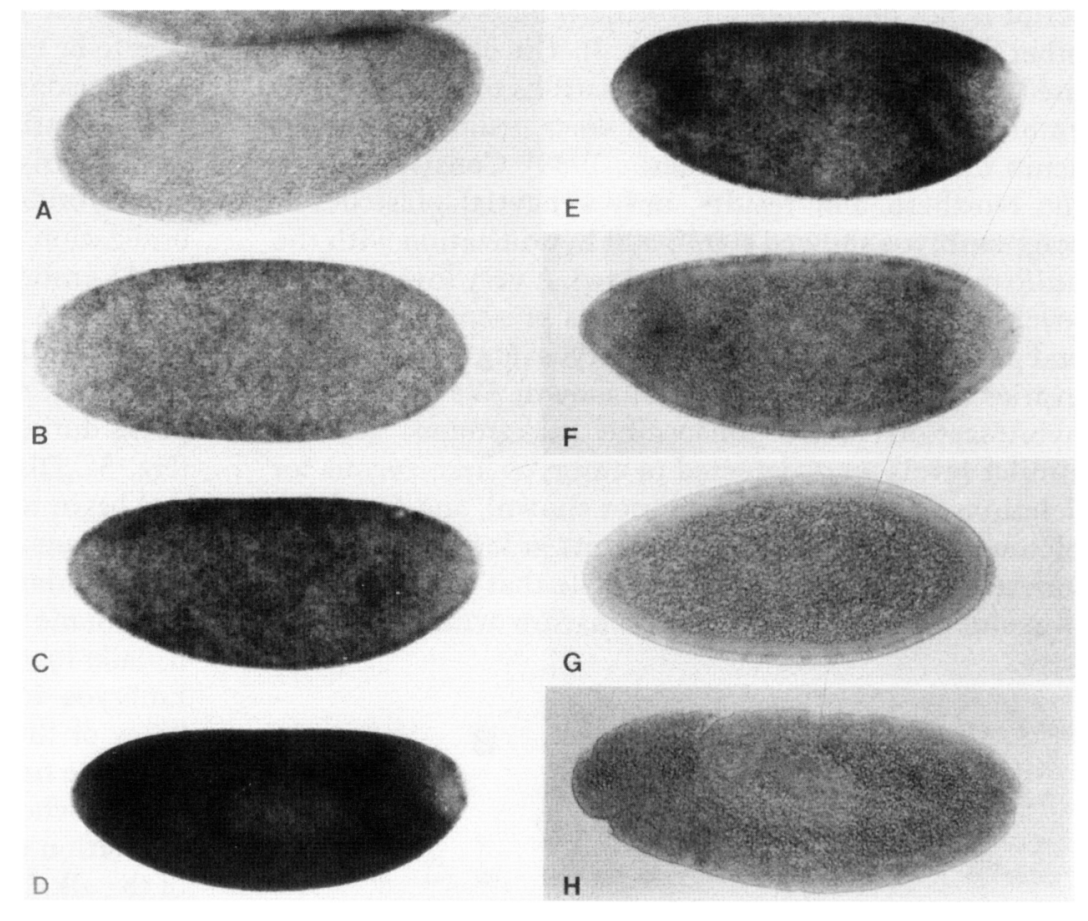

are located in the apical regions of the newly forming cells (Fig. 7B,C). The sry-alpha transcript levels decline during the rest of cellularization such that most early gastrulae have little or no detectable sry-alpha RNA. Thus, the peak in sry-alpha RNA accumulation is later than that observed for nullo RNA, corresponding to the time when nullo RNA accumulation is decreasing rapidly (Fig. 6C).

Given the similarity in the phenotypes of nullo and sry-alpha mutants, and the earlier peak in nullo RNA accumulation, we examined whether nullo gene activity is required for normal sry-alpha expression. A sry-alpha probe was hybridized to embryos derived from a balanced nullo deficiency stock. The expression pattern of sry-alpha RNA in phenotypically nullo embryos was similar to that in wild-type siblings, both with respect to levels and timing of RNA accumulation (Table 3; Fig. 7C,D). The appearance of the apical layer of sry-alpha RNA in nullo embryos was slightly disrupted. This was apparently the result of the unevenness of the exterior surface of the nullo embryos, as similar perturbations of sry-alpha RNA were seen in other embryos with uneven surfaces (e.g., maternal haploid embryos; Fig. 8F). In the reciprocal experiment, embryos from a sry-alpha deficiency stock were hybridized with a nullo probe. All embryos showed the wild-type pattern of nullo expression, indicating that those embryos deleted for sry-alpha expressed nullo normally (Table 3). (It should be noted that nullo RNA decays before the sry-alpha phenotype can be scored, and so transcript levels were scored in phenotypically normal embryos.) These results demonstrate that neither of these two genes is required for the normal transcription of the other. nullo RNA accumulation in other zygotic mutant backgrounds

In addition to nullo and sry-alpha, there are only three other regions of the genome that are required zygotically for normal cellularization. Two loci on the left arm of chromosome 2 are required for the slow phase and fast phase of membrane invagination but not for the structure of the hexagonal network. The phenotype produced by deletions of the bottleneck (blk) locus (on the right arm of chromosome 3), however, includes a disrupted actin-myosin network (Merrill et al. 1988; Wieschaus and Sweeton 1988). To determine whether any of these genes are required zygotically for nullo expression, in situ hybridizations were performed on embryos derived from the compound chromosome stocks $\mathrm{C}(2) \mathrm{v}$ and $\mathrm{C}(3)$ se. In these stocks, although the parents have the normal diploid complement, one-quarter of their embryos are deleted for either the left or the right arm of the chromosome (see Table 3). Similar experiments were performed using an attached-X chromosome stock bearing an autosomal insertion of the nullo gene [C(1)RM; $1 E]$, which produces embryos deleted for the $\mathrm{X}$ chromosome. The use of the compound chromosomes has the advantage of testing the entire $\mathrm{X}$, second and third chromosomes for genes required for normal nullo RNA accumulation, in addition to testing the requirements for particular cellularization genes.

Embryos derived from the stocks $\mathrm{C}(2) \mathrm{v}, \mathrm{C}(3)$ se, and C(1)RM; 1 E showed a normal accumulation of nullo transcripts to peak levels by the beginning of cycle 14 (Table 3 ). Thus, no zygotically acting genes appear to be required for the normal activation of nullo gene transcrip- 

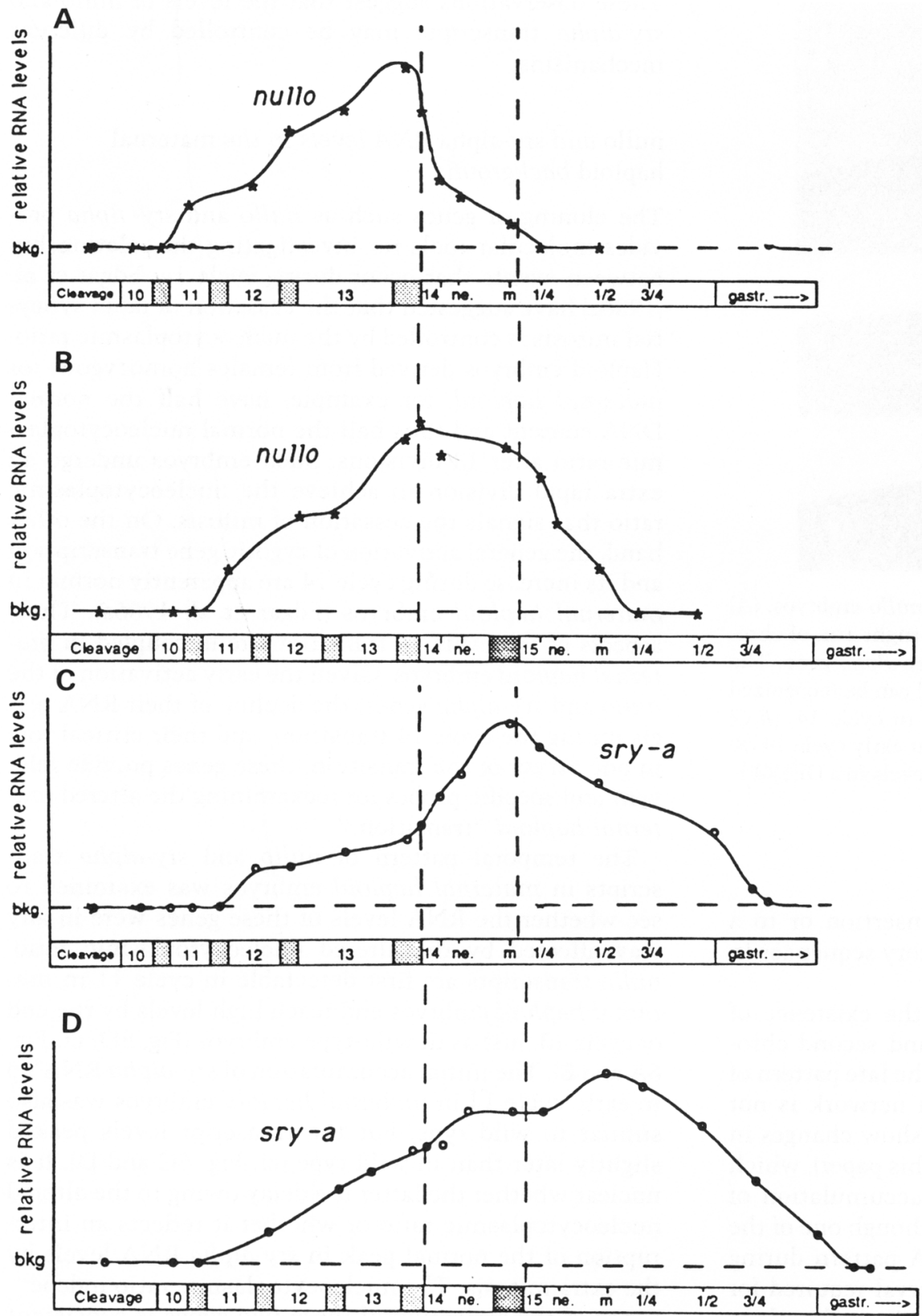

Figure 6. nullo and sry-alpha RNA levels in wild-type and maternal haploid embryos. Embryos were staged and scored for RNA levels as described in Materials and methods. The y-axis shows the relative level of RNA, plotted from the average score for embryos at each particular stage. (The similarity in height between the nullo and sry-alpha peaks does not indicate similarity in absolute levels of RNA.) The $\mathrm{x}$-axis displays developmental time from cycle 11 through the beginning of gastrulation. For wild type, scores for embryos were grouped at the following precellularization stages: cycles 11,12 , and 13, interphase (open bar), and mitosis (shaded). Cycle 14 embryos were grouped into substages corresponding to the onset of cycle 14, packed nuclei, nuclear elongation (ne), membrane invagination starting (m) membranes $1 / 4$ of full length, $1 / 2 \mid=$ to base of nuclei), $3 / 4$, full, and early gastrulation. For maternal haploid embryos, cycle 14 time points include onset, packed nuclei, nuclear elongation, and mitosis (shaded). During cycle 15 in maternal haploid embryos, the durations of stages of cellularization and gastrulation are the same as for wild-type cellularization. However, the earlier cell cycle durations are slightly different in maternal haploid embryos, and so the wild-type and the $m a$ ternal haploid $\mathrm{x}$-axes have been aligned at the cycle 13 mitosis. Vertical broken lines have been drawn at the cycle 13 mitosis and at the end of the maternal haploid extra mitosis to aid in the comparison of parts $A-D$. (A) The temporal profiles of nullo RNA levels derived from in situ hybridizations to Oregon-R embryos. $(B)$ nullo RNA levels in maternal haploid embryos. (C) The temporal profile of sry-alpha RNA levels. The sry-alpha profile is a composite of all in situ experiments shown in Table 3. These experiments showed a slight variation in the slope of sry-alpha accumulation during syncytial stages but were virtually identical during cycle $14 .(D)$ sry-alpha RNA levels in $m a-$ ternal haploid embryos. tion or the accumulation of nullo RNA to high levels. Although some late alterations in the spatial pattern of nullo RNA were observed, those changes do not appear to be the result of the deletion of genes required for cellularization (described below).

In some mutant genotypes, the pattern of nullo RNA appeared to be affected during the decline in RNA levels in cycle 14 . In $39 \%$ of the $\mathrm{C}(2) \mathrm{v}$-derived embryos, there were new bands of heavier RNA accumulation, in addition to those bands seen in wild-type embryos (cf. Fig. 8A and B). In situ hybridizations to embryos from additional crosses suggested that the alteration in the nullo RNA pattern was complicated in origin, apparently resulting from both extra copies of the right arm of chromosome 2 and the deletion of the 26B-F region of the left arm of chromosome 2 (for details, see Table 3). Although the RNA in some of the new bands may have persisted slightly longer than in wild type, the RNA levels ultimately decreased to background, always well before the end of cellularization. In addition, $18 \%$ of the C(1)RM; 1E cycle 14 embryos showed a slight shift in the position of the heavy bands (Fig. $8 \mathrm{C}$ ). Because only a portion of the C(1)RM;1E embryos showed the alterations, it seems unlikely that these latter results are due 


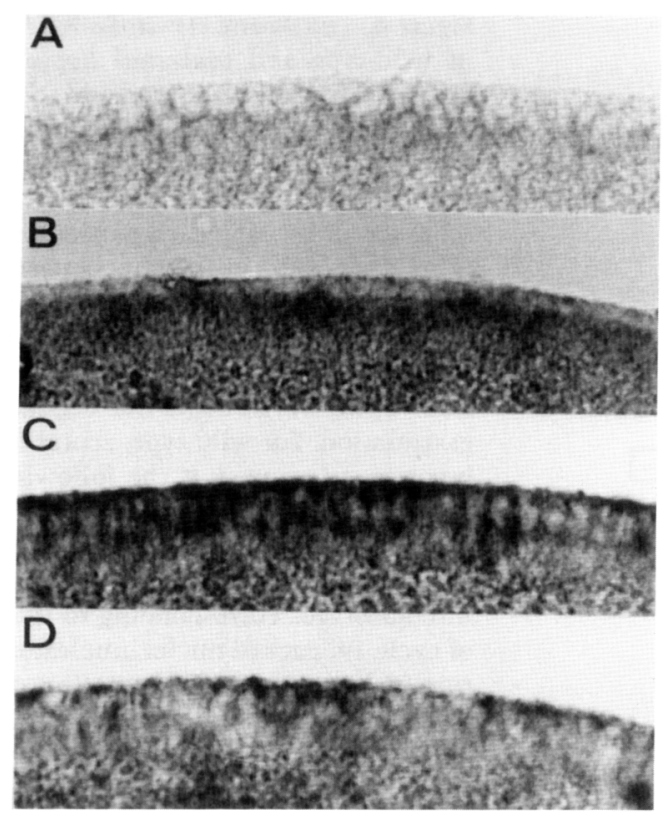

Figure 7. sry-alpha RNA in wild-type and nullo embryos. $|A|$ Absence of sry-alpha RNA in a control 3R - (right arm of chromosome 3 deleted) embryo that lacks the sry-alpha gene. The embryo is also deficient for the blk locus and can be recognized by the abnormal morphology of the nuclei in cycle $14 .(B, C)$ sry-alpha RNA levels in wild-type embryos at early cycle $14(B)$ and at cellularization $1 / 4(C)$. sry-alpha RNA levels in a Df(1)6Fl2 , nullo embryo, at cellularization $1 / 4(D)$.

either to a position effect of the $1 \mathrm{E}$ insertion or to a failure to include all of the nullo regulatory sequences in the 1E construct.

The above results together suggest the existence of zygotically expressed genes on the $\mathrm{X}$ and second chromosomes that participate in producing the late pattern of nullo RNA during cycle 14 . The actin network is not perturbed in any of the genotypes that show changes in nullo RNA pattern (Merrill et al. 1988; this paper), which is consistent with the earlier normal accumulation of nullo transcripts in these genotypes. Although one of the regions required for normal nullo RNA pattern during cycle 14 maps to $26 \mathrm{~B}-\mathrm{F}$ - the same interval required for the slow phase of membrane invagination-the alterations in nullo RNA pattern occur after the "slowphase" phenotype is first manifest (Merrill et al. 1988). It thus seems likely that there is a separate gene in $26 \mathrm{~B}-\mathrm{F}$ that is involved in either control of late nullo expression or nullo RNA stability.

To determine whether the normal expression of the sry-alpha gene requires the zygotic activity of any genes on the $\mathrm{X}$, second, or third chromosomes, $\mathrm{C}(2) \mathrm{v}, \mathrm{C}(3) \mathrm{se}$, and $\mathrm{C}(1) \mathrm{RM}$; $1 \mathrm{E}$ progeny were hybridized with a sry-alpha probe. (In these experiments, the right arm of chromosome 3 was not tested, as embryos deleted for $3 \mathrm{R}$ are deleted for the sry-alpha gene.) No changes in the normal accumulation of sry-alpha transcripts were observed in any of the genotypes examined (Table 3). Moreover, no late changes in the pattern of sry-alpha transcripts, comparable to those seen for nullo transcripts, were detected. These observations suggest that the levels of nullo and sry-alpha transcripts may be controlled by different mechanisms.

nullo and sry-alpha RNA levels in the maternal haploid background

The cloning of genes such as nullo and sry-alpha provides molecular tools for investigating the relationship between events that occur during cycle 14. Edgar et al. (1986a) have suggested that the cessation of rapid syncytial mitosis is controlled by the nucleocytoplasmic ratio. Haploid embryos derived from females homozygous for maternal haploid, for example, have half the normal DNA content and thus half the normal nucleocytoplasmic ratio after 13 divisions. Such embryos undergo an extra rapid division to achieve the nucleocytoplasmic ratio that signals the cessation of mitosis. On the other hand, the general activation of zygotic gene transcription and its increase during cycle 14 are apparently normal in maternal haploid embryos (Edgar et al. 1986a). Thus, aspects of the cycle 14 transition are uncoupled in maternal haploid embryos. Given the early activation of the nullo and sry-alpha genes, the decline of their RNA levels during the cycle 14 transition, and their critical role in one aspect of the transition, these genes provide relevant and specific probes for reexamining the altered maternal haploid "transition."

The temporal pattern of nullo and sry-alpha transcripts in maternal haploid embryos was examined to see whether the RNA levels of these genes were in any way affected by the altered nucleocytoplasmic ratio. nullo transcripts are first detectable in cycle 11 in $\mathrm{ma}$ ternal haploid embryos and reach high levels by the end of cycle 13, just as in wild-type embryos (Fig. 8D; cf. Fig. $6 \mathrm{~A}$ and $\mathrm{B}$ ). The initial accumulation of sry-alpha RNA up to early cycle 14 in maternal haploid embryos was also similar to wild type, but the transcript levels peaked slightly later than in wild type (cf. Fig. 6C and D). It is unclear whether the latter is a delay owing to the altered nucleocytoplasmic ratio or whether it reflects an interruption of the normal peak in sry-alpha RNA levels by the extra mitosis. The nucleocytoplasmic ratio independence of the activation of these two genes is consistent with observations that in spite of the extra division, a normal actin-myosin network forms at the onset of cycle 14 in maternal haploid embryos (D. Sweeton and E. Wieschaus, pers. comm.).

Although the initial accumulation of nullo and sryalpha transcripts are not affected by the nucleocytoplasmic ratio, the decrease in the transcript levels of both genes during cycle 14 is altered in maternal haploid embryos. Both nullo and sry-alpha RNA levels persist at high levels longer in maternal haploid embryos (Fig. $8 \mathrm{E}, \mathrm{F})$. For example, maternal haploid embryos show peak levels of nullo RNA during and immediately after the fourteenth (i.e., extra) mitosis; this corresponds to a time in wild-type embryos when nullo transcripts are 
Table 3. In situ hybridizations to nullo and sry-alpha transcripts

\begin{tabular}{|c|c|c|c|c|c|}
\hline \multirow[b]{3}{*}{ Cross $^{a}$} & \multicolumn{3}{|c|}{$\begin{array}{c}\text { In situ hybridizations } \\
\text { to nullo RNA }\end{array}$} & \multirow{2}{*}{\multicolumn{2}{|c|}{ 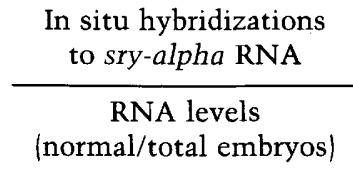 }} \\
\hline & \multicolumn{2}{|c|}{$\begin{array}{c}\text { RNA levels } \\
\text { (normal/total embryos) }\end{array}$} & \multirow{2}{*}{$\frac{\begin{array}{c}\text { spatial distribution } \\
\text { (altered/total embryos) }\end{array}}{\text { cycle } 14^{c}}$} & & \\
\hline & cycles 12,13 & cycle $14^{\mathrm{b}}$ & & cycles 12,13 & cycle $14^{\mathrm{b}}$ \\
\hline Oregon-R & $29 / 30$ & $23 / 24$ & - & ND & \\
\hline 6F1-2/FM7 × FM7/Y (1/4 nullo $\left.{ }^{-}\right)$ & $13 / 16$ & $15 / 22$ & 0 & $3 / 3$ & $72 / 72$ \\
\hline $\mathrm{X} 3 \mathrm{f} / \mathrm{TM} 3 \times \mathrm{X} 3 \mathrm{f} / \mathrm{TM} 3\left(\mathrm{I} / 4\right.$ sry-alpha $\left.{ }^{-}\right)$ & $13 / 13$ & $23 / 23$ & 0 & ND & \\
\hline $\mathrm{C}(3)$ se $\times \mathrm{C}(3)$ se $\left(1 / 4\right.$ sry-alpha,blk $\left.{ }^{-}\right)$ & $18 / 18$ & $30 / 30$ & 0 & $14 / 16$ & $53 / 62$ \\
\hline$C(2) v \times C(2) v^{d}\left\{1 / 4\right.$ slow and fast phase ${ }^{-} \mid$ & $24 / 24$ & $39 / 40$ & $17 / 43$ & $11 / 11$ & $44 / 44$ \\
\hline $\mathrm{C}(2) \mathrm{v} \times \mathrm{T}(2 ; \mathrm{Y}) 26 \mathrm{~F}^{\mathrm{d}}\left(1 / 826 \mathrm{~F}-\right.$ distal $\left.^{-}\right)$ & $45 / 45$ & $64 / 64$ & $25 / 57$ & ND & \\
\hline $\mathrm{C}(2) \mathrm{v} \times \mathrm{T}(2 ; \mathrm{Y}) 26 \mathrm{~B}^{\mathrm{d}}\left(1 / 826 \mathrm{~B}-\right.$ distal $\left.^{-}\right)$ & $14 / 14$ & $58 / 60$ & $29 / 55$ & ND & \\
\hline $\mathrm{C}(1) \mathrm{RM} / \mathrm{Y} ; 1 \mathrm{E} \times \mathrm{FM} 7 / \mathrm{Y} ; 1 \mathrm{E}\left(1 / 4 \mathrm{Y} / \mathrm{Y} ;\right.$ nullo $\left.^{+}\right)$ & $10 / 11$ & $36 / 38$ & $7 / 38$ & $6 / 6$ & $41 / 41$ \\
\hline
\end{tabular}

(ND) Not determined.

${ }^{a}$ Genotypes of interest produced by the crosses are shown beside them, using the following abbreviations: (sry-a) serendipity-alpha; (blk) bottleneck; (slow and fast phase) the loci required for those phases of membrane invagination; (26F-distal) synthetic deletion from $26 \mathrm{~F}$ to tip of $2 \mathrm{~L}$.

${ }^{\mathrm{b}}$ The number of embryos showing normal levels of nullo RNA as compared to Oregon-R. Here, normal levels include embryos with RNA in an altered distribution. For nullo RNA, cycle 12,13, and 14 embryos through the time when the nuclei are fully elongated are included, as these are the times during which nullo RNA is consistently detected. However, even in wild type (Oregon-R), an occasional early cycle 12 embryo or cycle 14 embryo late in nuclear elongation shows only background levels of hybridization. For sry-alpha, cycle 14 embryos through the end of cellularization were scored.

"The total number of embryos in the altered pattern category differs because very early cycle 14 embryos (prior to nuclear packing) could not be scored reliably for banding in wild-type or mutant crosses.

${ }^{\mathrm{d}} \mathrm{C}(2) \mathrm{v}$ progeny include $1 / 4$ deleted for either the left arm of chromosome $2(2 \mathrm{~L})$ or the right arm $(2 \mathrm{R})$ and a partially overlapping $1 / 4$ embryos that have four copies of $2 \mathrm{~L}$ or $2 \mathrm{R}$. C $(2) \mathrm{v} \times$ translocation $(2 \mathrm{~L} ; \mathrm{Y})$ males yield embryos of which $1 / 2$ have three copies of $2 \mathrm{R} ; 1 / 8$ of those embryos are also deleted for the region from the translocation break to the tip of $2 \mathrm{~L}$. [For details of compound and translocation chromosome segregation, see Merrill et al (1988).] Embryos derived from the C(2)v stock, some of which were identified as being deleted for $2 \mathrm{~L}$ based on the halo phenotype (Merrill et al. 1988), showed more bands of heavy nullo RNA accumulation than wild-type embryos. To determine whether this alteration was the result of being deleted for $2 \mathrm{~L}$ or carrying extra copies of $2 \mathrm{R}$, embryos from translocation socks were hybridized with a nullo probe. The number of embryos with altered nullo RNA patterns in the $\mathrm{C}(2) \mathrm{v} \times \mathrm{T}(2 ; \mathrm{Y})$ crosses is consistent with the number of embryos carrying three copies of the $2 \mathrm{R}$. Embryos from the $26 \mathrm{~F}$ cross identified by the halo phenotype as being deleted for $26 \mathrm{~F}$ to the tip of $2 \mathrm{~L}$ showed five bands of heavy RNA accumulation (see Fig. 5D). The rest of the altered embryos, and all of those from the $26 \mathrm{~B}$ cross with an altered RNA distribution, had only three bands (i.e., one extra compared with wild type). Embryos deleted for $2 \mathrm{~L}$ are deleted for both the slow-phase and fast-phase loci; the 26F synthetic deletion deletes the slow-phase locus, and 26B deletes neither.

decreasing rapidly. The eventual decrease in nullo and sry-alpha RNA levels in maternal haploid embryos follows a time course after the fourteenth mitosis that is similar to the decline observed in wild-type embryos after the thirteenth division. Thus, there is a delay of approximately one cell cycle in the decrease in the RNA levels of both genes in maternal haploid embryos (Fig. 6). The results suggest that the mechanisms controlling RNA persistence during the cycle 14 transition (e.g., degradation, repression) may be coupled to the nucleocytoplasmic ratio.

\section{Discussion}

Structure and function of the nullo gene

In this paper we describe the molecular isolation of nullo, a gene required zygotically for cellularization of the Drosophila embryo. Identification of the nullo gene was achieved by a combination of molecular mapping and transformation rescue of nullo mutations. Our pre- vious morphological examination of nullo mutants led us to speculate that the nullo gene is required for the stability of the hexagonal actin-myosin network during its contraction in cellularization. We postulated that nullo might be involved in increasing actin-actin interactions or membrane-to-cytoskeleton attachments (Simpson and Wieschaus 1990). The predicted protein sequence of the nullo gene provides little direct insight for either refining or refuting the stabilization model. The potential amino-terminal myristoylation of the protein could position the nullo protein near the cell membrane (Towler et al. 1988) for a role in membrane-to-cytoskeleton attachment. Future experiments will determine whether the protein is myristoylated or membrane associated. The most striking feature of the predicted protein is the high number of positively charged amino acid residues distributed throughout the primary sequence. Although a variety of proteins have high isoelectric points, basic residues are often diagnostic of proteins or domains of proteins that interact with nucleic acids, such as histones, protamines, and transcription factors (Lehninger 
Figure 8. Pattern of nullo and sry-alpha RNA in wild-type and mutant backgrounds. $(A-C)$ In situ hybridizations to nullo RNA in a wild-type embryo, early cycle $14(A)$, an embryo from $\mathrm{C}(2) \mathrm{v} \times \mathrm{T}(2 ; \mathrm{Y}) 26 \mathrm{~F}$ during nuclear elongation $(B)$, and an embryo from the C(1)RM/FM7/ Y; $1 E$ stock during nuclear elongation $(C)$. In $B$, five bands of nullo transcripts are visible. The anterior and posterior bands correspond in position to the heaviest accumulation of transcripts seen in wild type. The bands marked by arrowheads appear in embryos deleted for the 26B-F region but not in embryos from $\mathrm{C}(2) \mathrm{v} \times \mathrm{T}(2 ; \mathrm{Y}) 26 \mathrm{~B}$, which only show one additional band of heavy nullo RNA accumulation (arrow). This central band (arrow) apparently results from having three copies of the right arm of chromosome 2 (see Table 3). The embryo in $C$ shows two heavy bands of nullo RNA that appear to be shifted toward the center, relative to the wild-type pattern. $(D, E)$ nullo RNA levels in maternal haploid embryos at cycle 13 mitosis $(D)$ and cycle 14 (extra) mitosis $(E)$. $(F)$ sry-alpha RNA levels in a maternal haploid embryo at cellularization $1 / 2$; this corresponds to a time in wild-type development (full cellularization) when sry-alpha levels would be close to background (refer to Fig. 6). Staging of embryos was based on morphology and density of Hoechst-stained nuclei (data not shown).

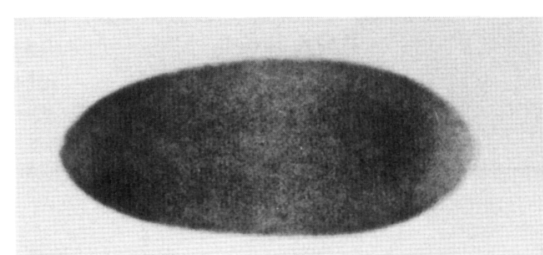

A

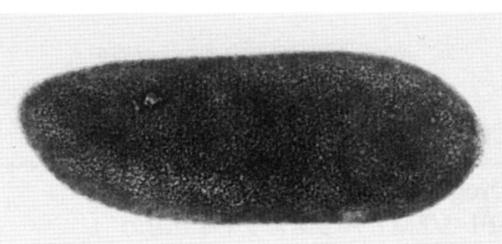

D

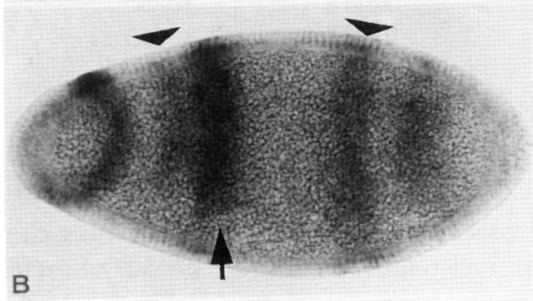

B

E

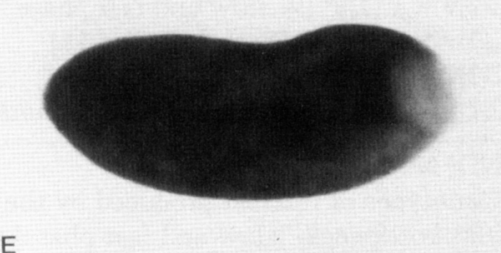

C

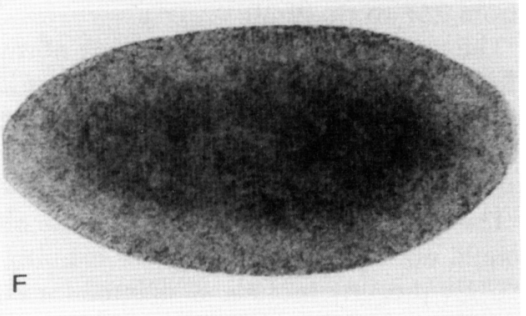

1978; Griffith and Pollard 1982; Busch and SassoneCorsi 1990). It is difficult to reconcile a role in chromatin structure with the nullo mutant phenotype. Furthermore, we believe a role in transcriptional control is unlikely. Deletion of only one other region of the genome, containing the sry-alpha gene, gives a mutant phenotype like that of nullo (Merrill et al. 1988; Wieschaus and Sweeton 1988; E. Wieschaus, unpubl.). Our in situ hybridizations showed that nullo activity is not necessary for sry-alpha expression, nor vice versa. We propose that both the nullo and sry-alpha products have more direct roles in cellularization, such as the stabilization function discussed above.

The control of nullo and sry-alpha transcript accumulation and its relationship

to the cycle 14 transition

The nullo and sry-alpha genes both produce blastodermspecific transcripts, but the levels of each peak at different times in cycle 14. Furthermore, nullo transcripts take on a banded appearance during cycle 14 in wild-type embryos, which is affected by certain deletions of the genome. The sry-alpha transcripts are uniform in distribution in all situations examined thus far. These results suggest that the mechanisms for controlling the details of the transcript patterns for the two genes are different. The banded pattern of nullo RNA, its resolution from an earlier more uniform distribution, and the changes in the pattern observed in mutant backgrounds are all reminiscent of the pattern of transcript accumulation observed for some gap and segmentation genes (Scott and Carroll 1987; Carroll 1990). Thus, it is possible that some aspect of nullo RNA regulation is shared with that used for the pattern formation genes. Regulation of the RNA patterns of gap and segmentation genes has been shown to result from both transcriptional activation and repression (and, in the case of fushi tarazu, at least, accompanied by rapid but uniform RNA degradation; Edgar et al. 1986b; Jäckle et al. 1986; Carroll 1990).

Despite the suggested differences in the control of the nullo and sry-alpha genes, both genes show a similar dependence on the nucleocytoplasmic ratio for their decline in RNA levels. Studies by Edgar et al. (1986a) argue that the nucleocytoplasmic ratio normally present at the onset of cycle 14 triggers the cessation of rapid synchronous cleavage mitoses. The overall activation of poly $(\mathrm{A})^{+}$RNA synthesis and its increase in cycle 14 , however, did not seem to be affected by alterations in the nucleocytoplasmic ratio. More recently, Yasuda et al. (1991) have examined the transcription of specific genes and have identified two classes: those whose transcript patterns are independent of the nucleocytoplasmic ratio, and those whose transcript patterns are dependent. The independent class is characterized by genes with zygotic transcription that begins early in cycle 14 or before $(A n$ tennapedia, P2 promoter; even-skipped). The dependent class consists of genes that undergo degradation of maternal transcripts (bicoid) or degradation of maternal transcripts coupled to a transition to zygotic transcription during cycle 14 (string and Toll). Although the activation of nullo and sry-alpha transcription is nucleo- 
cytoplasmic ratio independent, the decline in their RNA levels is dependent. The persistence of transcripts in maternal haploid embryos could indicate an effect of the nucleocytoplasmic ratio on the degradation of nullo and sry-alpha RNAs, as it must be for the maternal transcripts. How does the nucleocytoplasmic ratio affect RNA persistence? Yasuda et al. (1991) and O'Farrell et al. (1989) have suggested that the effect of the ratio is through the transcription of zygotic genes required for degrading maternal transcripts. The experiments reported here suggest that for the nullo gene, no zygotically acting genes on the $\mathrm{X}$, second, or third chromosomes are absolutely required for nullo RNA degradation, as nullo RNA levels declined well before gastrulation in all genotypes tested. We cannot, however, rule out subtle differences in RNA persistence.

Why might the rapid decline in nullo and sry-alpha RNA levels be important to the embryo? There is no hexagonal network to be stabilized during the conventional cytokinesis that occurs after cycle 14 . The presence of cellularization-specific proteins like nullo and sry-alpha might even have detrimental effects on these divisions. The decline in RNA levels that we observe during early cycle 14 may guarantee that nullo and sryalpha products are absent long before such conventional cell divisions begin. On the other hand, coupling this decline to the nucleocytoplasmic ratio ensures that nullo and sry-alpha transcripts do not decline until the cleavage nuclei have ceased to divide. It is at that point that cellularization normally occurs and at that point when the appropriate levels of the two gene products are required.

\section{Materials and methods}

Fly stocks

All of the nullo mutations used have been described (Simpson and Wieschaus 1990). The L-V-16.3(R15B) and L-II-27.32(R5) lines were recovered as male escapers from $\mathrm{LV16.3/FM7/Y} \mathrm{and}$ LII27.32/FM7/Y stocks, respectively, and mated to C(1)DX to generate new stocks; there appears to have been no change at the molecular level in either case. Although R5 shows a weaker phenotype than the parental stock, all R15B/Y embryos examined had phenotypes similar to the strongest phenotypes shown by L-V-16.3/Y embryos. The R15B mutation may no longer be fully penetrant, however, as only $20 \%$ of the embryos showed a nullo phenotype.

The crosses described in Table 3 used the following stocks: Df(1)6F1-2/FM7/Y (see above); Df(3)X3f/TM3, C(3)se, C(2)v, $\mathrm{T}(2 ; \mathrm{Y}) \mathrm{H} 121 \quad(26 \mathrm{~F}), \mathrm{T}(2 ; \mathrm{Y})) 136$ (26B), (Merrill et al. 1988); $\mathrm{C}(1) \mathrm{RM}, \mathrm{w} \mathrm{cv} / \mathrm{FM} 7 / \mathrm{Y}_{;}$nullo insertion $1 \mathrm{E}$ (Lindsley and Grell 1968; this paper). The maternal haploid mutation has been described (Gans et al. 1975; Zalokar et al. 1975). Oregon-R and Canton-S stocks were used for wild-type controls, and white embryos were used for P-element-mediated transformation rescue injections and for some wild-type in situ hybridizations (Lindsley and Grell 1968).

\section{Molecular characterization of deficiencies and Northern analysis}

Polytene chromosome squashes were prepared, hybridized with biotinylated probes, and visualized with streptavidin-HRP
(ENZO; Pardue 1986). J. Lim kindly provided $54 \mathrm{~kb}$ of DNA from the 6F1-2 region (F. Sheen, I. Lim, and M.J. Simmons, in prep.) in the form of four overlapping clones (Charon 4 vector, Canton-S genomic library). EcoRI restriction fragments from the walk (excluding the proximal $10-\mathrm{kb}$ that contained repetitive DNA) were subcloned into Bluescript (Stratagene). To generate the data in Figure 2, Southern blots of genomic DNA from adults heterozygous for nullo mutations and FM7, Canton-S, or $\mathrm{y}+\mathrm{ct}+\mathrm{Y}$ [which yielded restriction fragment-length polymorphisms (RFLPs)] or from homozygous nullo embryos (picked by phenotype during development) were probed with subcloned DNA. For example, LIMDF DNA failed to hybridize with probes on the left-hand portion of the map in Figure 2; the 1.2- and 4.5-kb EcoRI fragments hybridized to new RFLPs in LIMDF DNA, some of which were the same for both probes; the intervening DNA was present. This suggests that LIMDF contains an inversion between the 1.2- and 4.5-kb EcoRI fragments, in addition to the deletion. After transformation rescue was achieved, the results for most of the mutations were confirmed and extended by hybridization to Southern blots of DNA from rescued hemizygous nullo males [Df(1) ct78 could not be checked in this way, as it deletes other essential genes in addition to nullo]. Fly DNA was prepared according to Bender et al. (1983), electrophoresed on agarose gels, transferred to Nytran (Schleicher \& Schuell), and hybridized with nick-translated or random-primed probes. Unless noted otherwise, all molecular methods described in this and other sections were carried out using standard techniques as described in Maniatis et al. (1982) and Sambrook et al. (1989).

To determine regions that have transcripts present in 0 - to 4-hr embryos, cDNA was prepared from poly $(A)^{+}$RNA extracted from a 0- to 4-hr collection of Canton-S embryos, nicktranslated, and hybridized to Southern blots of the phage and subcloned DNA. Northern blots of poly $(\mathrm{A})^{+}$RNA were then hybridized with subclones spanning from the 5.6-kb EcoRI fragment (left) to the 6.0-kb EcoRI fragment (right). Only the 5.6and $4.5-\mathrm{kb}$ fragments showed detectable hybridization in these experiments. Because only the $4.5-\mathrm{kb}$ fragment has been used as a probe on developmental Northern blots, we do not know whether transcription units expressed at other times are also in this region. Total RNA was prepared by the hot phenol extraction method (Jowett 1986) or following the procedure outlined in the FastTrack RNA extraction kit (Invitrogen); poly $(\mathrm{A})^{+}$was extracted by oligo(dT) chromatography (FastTrack, Invitrogen). RNA was electrophoresed on formaldehyde gels, transferred to NitroWest; and hybridized as outlined in Parks et al. (1986), with nick-translated or random-primed probes. One experiment utilized a single-stranded DNA probe (Sambrook et al. 1989; see lengend to Fig. 4) synthesized from the EcoRI-HindIII fragment of the cDNA (M1, Brown library), which included a small amount of flanking vector sequences.

\section{Transformation}

The 4.5-kb EcoRI fragment was subcloned into the white ${ }^{+}$ transformation vector pW8 (Klemenz et al. 1987). Cesium-purified DNA was coinjected into white embryos with the transposition helper P-turbo (Spradling 1986). Surviving adults were crossed to white flies, and their progeny were screened for white ${ }^{+}$transformants. Two white ${ }^{+}$lines were established: one line bearing both an X-linked and an autosomal insertion, which were subsequently separated, and a second line bearing an X-linked insertion. The X-linked lines were recombined onto the mutant chromosomes R15B (insertion 1A) and LII27.32 (51A) by scoring for nearby markers. The presence of the original nullo mutant lesion in the recombinants was confirmed by 
Southern analysis (not shown). The autosomal insertion (1E) was crossed to several nullo mutant stocks to establish new lines and score for rescue of lethality. FM7/Y;1E males from this were crossed to attached-X [C(1)RM] females to establish a $\mathrm{C}(1) \mathrm{RM} / \mathrm{Fm} 7 / \mathrm{Y}$; $1 \mathrm{E}$ stock. To determine the cellularization phenotype of nullo; $1 \mathrm{E}$ insertion lines, embryos from LIMDF/FM7/ $\mathrm{Y} ; 1 \mathrm{E} / 1 \mathrm{E}$ were fixed and stained with rhodamine-phalloidin and Hoescht (see Simpson and Wieschaus 1990). The state of the actin network and nuclei was examined by fluorescence microscopy. Progeny from the C(1)RMilE stock were examined for their nuclear morphology only (i.e., the clumping together that is indicative of multinucleate cells); in addition, embryos with normal cells but showing the folded gastrulation phenotype (and, therefore, of genotype $\mathrm{Y} / \mathrm{Y} ; 1 \mathrm{E}$ ) were observed

\section{Isolation of cDNAs, sequencing, and sequence analysis}

Three cDNAs ( $M 1, M 3$, and $1 \mathrm{~A}$ ) from a 0 - to 4 -hr library (Brown and Kafatos 1988) and one (14A) from a separate library (M. Noll, unpubl.) were isolated using the $4.5-\mathrm{kb} E c o$ RI fragment as a probe. The EcoRI-HindIII fragment of pNB40-M1, containing the M1 cDNA insert, was subcloned into Bluescript $|+|$ and Bluescript (-); the EcoRI cDNA insert from 14A was cloned into Bluescript $(+1$. Further subclones of these and the genomic 4.5$\mathrm{kb}$ fragment were used for sequencing. Single-stranded DNA prepared from each (Sambrook et al. 1989) was sequenced by the dideoxy method (Sanger 1977) using Sequenase (U.S. Biochemical); gaps in the sequence, as well as the $5^{\prime}$ genomic region, were completed using oligonucleotide primers designed from the sequence (synthesized by the Princeton Molecular Biology Sequencing Facility). The entire MI cDNA was sequenced on both strands, and the 14A cDNA and the genomic DNA was sequenced on at least one strand. Approximately 100-200 nucleotides of $5^{\prime}$ and $3^{\prime}$ sequence of the $\mathrm{M} 3$ and $1 \mathrm{~A}$ cDNAs were determined by double-stranded sequencing. The lengths of the $5^{\prime}$ vector linkers and poly (A) tails showed these cDNAs to be independent from each other and $\mathrm{Ml}$.

Sequence analysis was carried out using the computer programs of Staden (1980), and the Wisconsin Genetics Computer Group Package (Devereux 1984). Searches of GenBank and EMBL used the FASTA program (Pearson and Lipman 1988). The potential myristoylation site was identified through the use of the Pro-Site dictionary (Bairoch 1991).

\section{Whole-mount in situ hybridization}

Whole-mount in situ hybridizations were carried out according to the protocol of Tautz and Pfeifle (1989), using digoxigenin probes (Boehringer Mannheim) prepared by random priming with 10 times the normal concentration of oligonucleotides $(R$. Garber, unpublished modifications of Feinberg and Vogelstein 1983). The EcoRI-HindIII fragment of the M1 cDNA was labeled to produce nullo probes; a NcoI fragment containing genomic DNA from the sry-alpha gene was used to produce sryalpha probes (derived from pSMD7, kindly provided by Francois Schweisguth). After completion of the in situ procedure, embryos were incubated in $1 \mu \mathrm{g} / \mathrm{ml}$ of Hoescht 33258 in PBS for 10 min to visualize the nuclei.

To produce the graphs in Figure 6, the darkness of the alkaline phosphatase reaction precipitate was scored on a scale of 1 to 10 , using visual inspection of embryos under bright-field microscopy. Embryos were staged by nuclear density and counting the number of nuclei along a dorsal longitudinal optical cross section, using numbers based on Zalokar and Erk [(1976): cycle 11, $<30$ nuclei; cycle $12,35-50$; cycle $13,50-70$; cycle $14,70-95$; maternal haploid "15">100). Cycle 14 embryos were further staged as to whether the nuclei had become hexagonally packed at the onset of cycle 14, the extent of nuclear elongation, and the presence and extent of membrane invagination. To produce the time line on the $\mathrm{x}$-axis, the durations of interphase and mitosis for wild-type and maternal haploid embryos (from Foe and Alberts 1983; Edgar et al. 1986a) were plotted to scale; times for cellularization events were derived from time-lapse videos of wild-type embryos and maternal haploid embryos. The developmental stage was plotted against the hybridization levels, with the average level of all embryos in each stage providing the points through which the curve was drawn.

\section{Acknowledgments}

We are indebted to Johng Lim for providing us with the $\lambda$ clones from the $6 \mathrm{~F} 1-2$ region and sharing information with us throughout the course of this work. We are also grateful to Fang-miin Sheen and Michael Simmons for stocks and for sharing data prior to publication, and to Francois Schweisguth for providing the sry-alpha plasmid. We thank Mark Peifer, Eyal Schejter, Trudi Schüpbach, and Marya Postner for critically reading the manuscript, Romy Knittel for help with embryo collections, and Dari Sweeton for photographic prints. L.S.R. thanks K. Kemphues and R. Last for the use of facilities during the final stages of this work, and all the members of the Wieschaus and Schüpbach laboratories for their encouragement and support. This work was funded by grant 5R 37HD 15587 from the National Institutes of Health (NIH) to E.W.; L.S.R. was supported in part by NIH Cell and Molecular Biology training grant 5T32GM07312.

The publication costs of this article were defrayed in part by payment of page charges. This article must therefore be hereby marked "advertisement" in accordance with 18 USC section 1734 solely to indicate this fact.

\section{References}

Aota, S., T. Gojobori, F. Ishibashi, T. Maruyama, and T. Ikemura. 1988. Codon usage tabulated from the GenBank Sequence Data. Nucleic Acids Res. (Suppl.) 16: R315-R402.

Bairoch, A. 1991. Prosite: A dictionary of sites and patterns in proteins. Nucleic Acids Res. (Suppl.) 19: 2241-2245.

Bender, W., P. Spierer, and D.S. Hogness. 1983. Chromosomal walking and jumping to isolate DNA from the Ace and rosy loci and the Bithorax complex in Drosophila melanogaster. I. Mol. Biol. 168: 17-33.

Brown, N.H. and F.C. Kafatos. 1988. Functional cDNA libraries from Drosophila embryos. J. Mol. Biol. 203: 425-437.

Brown, N.H., D.L. King, M. Wilcox, and F.C. Kafatos. 1989. Developmentally regulated alternative splicing of Drosophila integrin PS2 alpha transcripts. Cell 59: 185-195.

Busch, S.J. and P. Sassone-Corsi. 1990. Dimers, leucine zippers, and DNA-binding domains. Trends Genet. 6: 3640-3643.

Carroll, S.B. 1990. Zebra patterns in fly embryos: Activation of stripes or repression of interstripes? Cell 60: 9-16.

Cavenar, D.R. 1987. Comparison of the consensus sequence flanking translational start sites in Drosophila and vertebrates. Nucleic Acids Res. 15: 1353-1361.

Devereux, J., P. Haeberli, and O. Smithies. 1984. A comprehensive set of sequence analysis programs for the VAX. Nucleic Acids Res. 12: 387-395.

Edgar, B.A., C.P. Kiehle, and G. Schubiger. 1986a. Cell cycle control by the nucleo-cytoplasmic ratio in early Drosophila development. Cell 44: 365-372.

Edgar, B.A., M.P. Weir, G. Schubiger, and T. Kornberg. 1986b. 
Repression and turnover pattern fushi tarazu RNA in the early Drosophila embryo. Cell 47: 747-754.

Feinberg, A.P. and B. Vogelstein. 1983. A technique for radiolabeling DNA restriction endonuclease fragments to high specific activity. Anal. Biochem. 132: 6-13.

Foe, V.E. and B.M. Alberts. 1983. Studies of nuclear and cytoplasmic behavior during the five mitotic cycles that precede gastrulation in Drosophila embryogenesis. J. Cell Sci. 61: $31-70$.

Fullilove, S.L. and A.G. Jacobson. 1971. Nuclear elongation and cytokinesis in Drosophila montana. Dev. Biol. 26: 560 577.

Gans, M., C. Audit, and M. Masson. 1975. Isolation and characterization of sex-linked female-sterile mutants in Drosophila melanogaster. Genetics 81: 683-704.

Griffith, L.M. and T.D. Pollard. 1982. Cross-linking of actin filament networks by self-association and actin-binding macromolecules. J. Biol. Chem. 257: 9135-9142.

Hultmark, D., R. Klemenz, and W. Gehring. 1986. Translational and transcriptional control elements in the untranslated leader of the heat-shock gene hsp22. Cell 44: 429-438.

Jäckle, H., D. Tautz, E. Siefert, and R. Lehmann. 1986. Crossregulatory interactions among the gap genes of Drosophila. Nature 324: 668-670.

James, A.A. and A. Vincent. 1986. The spatial distribution of a blastoderm stage-specific mRNA from the serendipity locus of Drosophila melanogaster. Dev. Biol. 118: 474-479.

Jowett, T. 1986. Preparation of nucleic acids. In Drosophila: $A$ practical approach (ed. D.B. Roberts), pp. 275-286. IRL Press, Oxford, England.

Karess, R.E., X. Chang, K.A. Edwards, S. Kulkarni, I. Aguilera, and D.P. Kiehart. 1991. The regulatory light chain of nonmuscle myosin is encoded by spaghetti-squash, a gene required for cytokinesis in Drosophila. Cell 65: 1177-1189.

Karr, T.L. and B.M. Alberts. 1986. Organization of the cytoskeleton in early Drosophila embryos. I. Cell Biol. 102: 1494 1509.

Katoh, K. and H. Ishikawa. 1989. The cytoskeletal involvement in cellularization of the Drosophila melanogaster embryo. Protoplasma 150: 83-95.

Ketchum, A.S., C.T. Stewart, M. Stewart, and D.P. Kiehart. 1990. Complete sequence of the Drosophila nonmuscle myosin heavy-chain transcript: Conserved sequences in the myosin tail and differential splicing in the 5'-untranslated sequence. Proc. Natl. Acad. Sci. 87: 663-667.

Klemenz, R., U. Weber, and W.J. Gehring. 1987. The white gene as a marker in a new P-element vector for gene transfer in Drosophila. Nucleic Acids Res. 15: 3947-3959.

Lehninger. A.L. 1978. Biochemistry, 2nd ed. Worth Publishers, New York.

Lindsley, D.L. and E.L. Grell. 1968. Genetic variations of Drosophila melanogaster. Carnegie Inst. Washington Publ. 627.

Maniatis, T., E.F. Fritsch, and J. Sambrook. 1982. Molecular cloning: A laboratory manual. Cold Spring Harbor Laboratory Press, Cold Spring Harbor, New York.

Merrill, P.T., D. Sweeton, and E. Wieschaus. 1988. Requirements for autosomal gene activity during precellular stages of Drosophila melanogaster. Development 104: 495-509.

Miller, K.G., C.M. Field, and B.M. Alberts. 1989. Actin-binding proteins from Drosophila embryos: A complex network of interacting proteins detected by f-actin affinity chromatography. J. Cell Biol. 109: 2963-2975.

O'Farrell, P.H., B.A. Edgar, D. Lakich, and C.F. Lehner. 1989. Directing cell division during development. Science 246: 635-640.

Pardue, M.L. 1986. In situ hybridization to DNA of chromo- somes and nuclei. In Drosophila: A practical approach (ed. D.B. Roberts). pp. 111-138. IRL Press, Oxford, England.

Parks, S., B. Wakimoto, and A. Spradling. 1986. Replication and expression of an X linked cluster of Drosophila chorion genes. Dev. Biol. 117: 294-305.

Pearson, W.R. and D.J. Lipman. 1988. Improved tools for biological sequence comparison.. Proc. Natl. Acad. Sci. 85: 2444-2448.

Sambrook, I., E.F. Fritsch, and T. Maniatis. 1989. Molecular cloning: A laboratory manual, 2nd ed. Cold Spring Harbor Laboratory Press, Cold Spring Harbor, New York.

Sanger, F., S. Nicklen, and A.R. Coulson. 1977. DNA sequencing with chain-terminating inhibitors. Proc. Natl. Acad. Sci. 74: 5463-5467.

Schweisguth, F., C. Yanicostas, F. Payre, J.-A. Lepesant, and A. Vincent. 1989. Cis-regulatory elements of the Drosophila blastoderm-specific serendipity alpha gene: Ectopic activation in the embryonic PNS promoted by the deletion of an upstream element. Dev. Biol. 136: 181-193.

Schweisguth, F., J.-A. Lepesant, and A. Vincent. 1990. The serendipity alpha gene encodes a membrane-associated protein required for the cellularization of the Drosophila embryo. Genes \& Dev. 4: 922-931.

Scott, M.P. and S.B. Carroll. 1987. The segmentation and homeotic gene network in early Drosophila development. Cell 51: 689-698.

Sheen, F. 1990. "Genetic and molecular analysis of mutations derived from an unstable X chromosome of Drosophila melanogaster." Ph.D. thesis. University of Minnesota, St. Paul.

Simpson, L. and E. Wieschaus. 1990. Zygotic activity of the nullo locus is required to stabilize the actin-myosin network during cellularization in Drosophila. Development 110: $851-863$.

Spradling, A.C. 1986. P element-mediated transformation. In Drosophila: A practical approach (ed. D.B. Roberts). pp. 175198. IRL Press Oxford, England.

Spradling, A. and G.M. Rubin. 1982. Transposition of cloned P elements into Drosophila germ line chromosomes. Science 218: $341-347$.

Staden, R. 1980. Automation of the computer handling of gel reading data produced by the shotgun method of DNA sequencing. Nucleic Acids Res. 8: 3673-3694.

Tautz, D. and C. Pfeifle. 1989. A non-radioactive in situ hybridization method for the localization of specific RNAs in the Drosophila embryo reveals translational control of the segmentation gene hunchback. Chromosoma 98: 81-85.

Towler, D.A., J.I. Gordon, S.P. Adams, and L. Glaser. 1988. The biology of eukaryotic protein acylation. Annu. Rev. Biochem. 57: 69-99.

Warn, R.M. and R. Magrath. 1983. F-actin distribution during the cellularization of the Drosophila embryo visualized with FL-phalloidin. Exp. Cell Res. 143: 103-114.

Warn, R.M. and M. Robert-Nicoud. 1990. F-actin organization during the cellularization of the Drosophila embryo as revealed with a confocal laser scanning microscope. $J$. Cell Biol. 96: 35-42.

Warn, R.M., B. Bullard, and R. Magrath. 1980. Changes in the distribution of cortical myosin during the cellularization of the Drosophila embryo. I. Exp. Embryol. Morphol. 57: 167176.

Warn, R.M., R. Magrath, and S. Webb. 1984. Distribution of f-actin during cleavage of the Drosophila syncytial blastoderm. I. Cell Biol. 98: 156-162.

Wieschaus, E. and D. Sweeton. 1988. Requirements for X-linked zygotic gene activity during cellularization of early Drosophila embryos. Development 104: 483-493. 
Yasuda, G., K. Baker, and G. Schubiger. 1991. Temporal regulation of gene expression in the blastoderm Drosophila embryo. Genes \& Dev. 5: 1800-1812.

Young, P.E., T.C. Pesacreta, and D.P. Kiehart. 1991. Dynamic changes in the distribution of cytoplasmic myosin during Drosophila embryogenesis. Development 111: 1-14.

Zalokar, M. and I. Erk. 1976. Division and migration of nuclei during early embryogenesis of Drosophila melanogaster. J. Microsc. Biol. Cell. 25: 97-106.

Zalokar, M., C. Audit, and I. Erk. 1975. Developmental defects of female-sterile mutants of Drosophila melanogaster. Dev. Biol. 47: 419-432. 


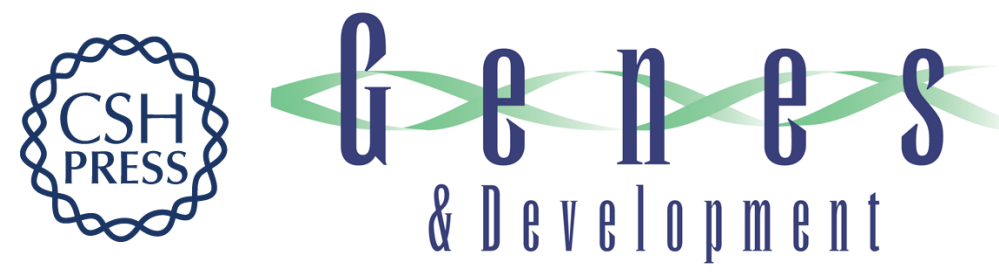

\section{The Drosophila cellularization gene nullo produces a blastoderm-specific transcript whose levels respond to the nucleocytoplasmic ratio.}

\section{S Rose and E Wieschaus}

Genes Dev. 1992, 6:

Access the most recent version at doi:10.1101/gad.6.7.1255 $\begin{array}{ll}\text { References } & \begin{array}{l}\text { This article cites } 47 \text { articles, } 17 \text { of which can be accessed free at: } \\ \text { http://genesdev.cshlp.org/content/6/7/1255.full.html\#ref-list-1 }\end{array}\end{array}$

License

Email Alerting Service

Receive free email alerts when new articles cite this article - sign up in the box at the top right corner of the article or click here.

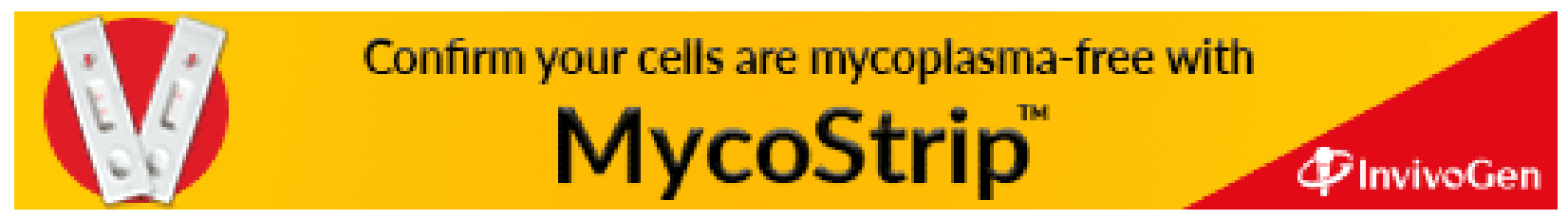

